\title{
Thelytoky in Cape honeybees (Apis mellifera capensis) is controlled by a single recessive locus
}

\author{
Denise Aumer ${ }^{1}$, Mike H. AllsopP ${ }^{2}$, H. Michael G. LattorfF ${ }^{1,4}$, \\ Robin F. A. Moritz ${ }^{1,3,4}$, Antje Jarosch-Perlow ${ }^{1}$ \\ ${ }^{1}$ Department of Molecular Ecology, Martin-Luther University Halle-Wittenberg, Hoher Weg 4, 06099, Halle (Saale), \\ Germany \\ ${ }^{2}$ Honeybee Research Section, ARC Plant Protection Research Institute, Private Bag X5017, Stellenbosch 7599, South \\ Africa \\ ${ }^{3}$ Department of Zoology and Entomology, University of Pretoria, Private Bag X20 Hatfield, Pretoria 0028, South Africa \\ ${ }^{4}$ German Centre for Integrative Biodiversity Research (iDiv) Halle-Jena-Leipzig, Deutscher Platz 5e, 04103, Leipzig, \\ Germany
}

Received 2 June 2016 - Revised 1 November 2016 - Accepted 21 November 2016

\begin{abstract}
Worker reproduction in Apis mellifera typically leads to haploid males produced via arrhenotokous parthenogenesis. An exception are laying workers of the South African Cape honeybee Apis mellifera capensis. Due to an abnormal spindle rotation during meiosis $A . m$. capensis workers are able to produce female progeny via thelytokous parthenogenesis. This trait has been suggested to be genetically controlled by a recessive allele at the thelytoky locus $(t h)$, but this conclusion was recently challenged by Chapman et al. (2015). To clarify the mode of inheritance for thelytokous parthenogenesis in Cape honeybees, we determined the sex of the offspring of 74 A.m. capensis workers of a single queen from a colony of the endemic wild population at the Cape of Good Hope Nature Reserve. When we tested individual worker reproduction, parthenogenesis was dimorphic, segregating in a Mendelian fashion supporting the single locus model. We could exclude maternal or paternal effects determining the mode of parthenogenesis. A careful re-analysis of the data of Chapman et al. (2015) also revealed that their data do not contradict the one locus model for the inheritance of thelytoky.
\end{abstract}

\section{thelytoky / worker reproduction / reproductive dominance / asexual reproduction / gemini}

\section{INTRODUCTION}

The female worker caste of the honeybee (Apis mellifera spp.) typically does not reproduce (Lattorff and Moritz 2013) in the presence of the pheromones produced by the queen (Butler 1959; Slessor et al. 1988; Plettner et al. 1993; Winston

Electronic supplementary material The online version of this article (doi:10.1007/s13592-016-0484-0) contains supplementary material, which is available to authorized users.

Corresponding author: D. Aumer, denise.aumer@zoologie.uni-halle.de Handling Editor: Stan Schneider and Slessor 1998) and the brood (Arnold et al. 1994). Whenever the queen and her pheromonal control are absent, workers are able to activate their ovaries and parthenogenetically produce haploid male offspring (arrhenotoky) (Crozier 1975; Ruttner and Hesse 1981; Winston 1987; Page and Erickson 1988; Visscher 1989). A rare exception to worker arrhenotoky is the parthenogenetic production of female offspring (thelytoky) by laying workers, which is a characteristic of Apis mellifera capensis (Eschscholtz, 1822), the Cape honeybee (Onions 1912; Anderson 1963). In this subspecies, an incomplete meiotic division based on an abnormal spindle orientation in anaphase II results in a central fusion of the meiotic products restoring egg diploidy (automixis with 
central fusion; Verma and Ruttner 1983) and hence female offspring.

This exceptional trait was claimed to be under genetic control of a single recessive allele because of suggestive Mendelian segregation (Ruttner 1988), which was subsequently confirmed in a controlled laboratory experiment (Lattorff et al. 2005). Based on a backcross mapping population and using the segregation of a set of 566 microsatellites, a recessive locus ( $t h$ ) on chromosome 13 was identified to be significantly linked with thelytokous parthenogenesis (Lattorff et al. 2007). This region spans $11.4 \mathrm{cM}$ (180 kb), comprises 15 genes (NCBI; Genome assembly Amel 4.5) and was genetically linked to rapid ovary activation and the production of high levels of the queen substance pheromone 9-oxo-2-(E)decenoic acid (9-ODA). Finally, Jarosch et al. (2011) showed that alternative splicing of gemini, a CP2 transcription factor in the target region, correlates with different reproductive states in $A$. $m$. carnica and also with the different modes of parthenogenesis. Moreover, RNAi knock-down studies proved the alternatively spliced exon 5 to control ovary activation in $\boldsymbol{A} . \boldsymbol{m}$. carnica workers. An adjacent intronic deletion of $9 \mathrm{bp}$ (thelytoky associated element; tael), present in the parasitic thelytokous $\boldsymbol{A} . \boldsymbol{m}$. capensis clone (Baudry et al. 2004), was proposed to control the process of alternative splicing and serves as the genetic switch determining the mode of parthenogenesis. More recently, however, Chapman et al. (2015) reported that thelytoky in A. $m$. capensis workers is not under single locus control. Specifically, they report the segregation of alleles at various markers flanking gemini (Shaibi et al. 2008; Jarosch et al. 2011) not to be associated with thelytoky.

In order to clarify the mode of inheritance of thelytoky in A. m . capensis workers, two complementary strategies were used in this study:

1. The segregation of different modes of parthenogenesis was assessed in a new mapping population using individual workers from a single naturally mated $A$. $m$. capensis queen. As a result of the high mating frequencies in A . $\boldsymbol{m}$. capensis (Kraus et al. 2004), the experimental workers represent a reasonable subsample of the $\boldsymbol{A}$. $\boldsymbol{m}$. capensis population as they comprise not only the queen's genotype but also those of many siring drones. To avoid a pheromonal arms race resulting in reproduction of the most dominant thelytokous worker (Moritz et al. 1996, 2000, 2004, 2008; Härtel et al. 2011), the workers were tested in an experimental setting free of intra-colonial selection for reproductive dominance to determine the mode of parthenogenesis of individual workers.

2. A careful re-analysis of the genotype data provided by Chapman et al. (2015) was conducted to test its consistency with a single locus model.

\section{METHODS}

\subsection{A . m . capensis laying workers}

Sealed worker brood frames of a wild $\boldsymbol{A} . \boldsymbol{m}$. capensis colony from the Cape of Good Hope section of the Table Mountain National Park (34 $\left.14^{\prime} 45.0^{\prime \prime} \mathrm{S} 18^{\circ} 24^{\prime} 15.0^{\prime \prime} \mathrm{E}\right)$ were brought to Stellenbosch and kept in an incubator $\left(37^{\circ} \mathrm{C}\right.$, $60 \%$ r. h.). Freshly emerged workers were collected daily, individually labelled with Opalith bee tags (Graze) on their thorax and colour marks on their abdomen (painted with uniball POSCA markers PC5M) and their wings clipped in order to prevent drifting into other colonies. These workers were individually introduced into a small group of newly emerged $\boldsymbol{A}$. $\boldsymbol{m}$. scutellata (Lepeletier, 1836) host workers where the $A . m$. capensis worker develops into a pseudoqueen to become the only reproductive individual (Neumann and Hepburn 2002).

\subsection{A.m . scutellata host colonies}

Twenty A . m . scutellata colonies from Douglas $\left(28^{\circ} 48^{\prime} 30.0^{\prime \prime} \mathrm{S} 23^{\circ} 50^{\prime} 30.0^{\prime \prime} \mathrm{E}\right)$ were brought to Stellenbosch. Multiple frames of emerging A . $m$. scutellata brood were placed in an incubator and emerged workers were collected every $24 \mathrm{~h}$. About 1000 individuals each were used to set up small queenless colonies in Apidea ${ }^{\circledR}$ mating nucs, provided with three combs containing 
honey, pollen and empty space for eggs. A single freshly emerged, individually marked and wing clipped $\boldsymbol{A} . \boldsymbol{m}$. capensis worker was introduced into every colony $(N=74)$. Colonies were kept inside (but closed) in a room at $28^{\circ} \mathrm{C}$ and $60 \% \mathrm{RH}$ for 2 days. Thereafter, the colonies were transported and opened in bee-tight netted cages to exclude invasion of foreign parasitic workers into the experimental colonies (Moritz et al. 2008, 2011). Every 2 days, the colonies were checked for the presence of the marked $\boldsymbol{A} . \boldsymbol{m}$. capensis worker and any brood. Newly emerged $A . m$. scutellata workers were added to the colonies when necessary to make sure that the $\boldsymbol{A} . \boldsymbol{m}$. capensis worker is accompanied by a sufficient number of $\boldsymbol{A} . \boldsymbol{m}$. scutellata host workers all the time. Bee-collected pollen and sugar candy were added when necessary to sustain the colonies. As soon as the first larvae hatched, but at the latest after 14 days, the marked $\boldsymbol{A}$. $\boldsymbol{m}$. capensis worker and all the brood (eggs and larvae) were collected and stored at $-20{ }^{\circ} \mathrm{C}$ for subsequent microsatellite genotyping to assess maternity and to identify the ploidy of the offspring to discriminate between male (haploid) and female sex (diploid). If the A. m. capensis worker died before collection all $\boldsymbol{A}$. $\boldsymbol{m}$. scutellata workers were sacrificed and the nuc was re-started.

\subsection{Genotyping}

DNA was solvent extracted from half of the flight muscle of each $A . m$. capensis worker ( $N=74)$ and their brood (1-9 eggs or larvae) using phenol-chloroform (Kirby 1956). Genotyping was done using seven polymorphic unlinked microsatellite markers (A107, A79, A113, A14, A28, A88, A35; Solignac et al. 2003) and five linked microsatellite markers flanking gemini (AT012, K1363, Hb-the 2, 3, 4; Shaibi et al. 2008) and the tae intronic region of gemini (tae; Jarosch et al. 2011). PCRs were conducted following standard protocols (Solignac et al. 2003) and subsequently analysed in a MegaBace®1000 (GE Health Care) automatic capillary sequencer following the instructions of the manufacturer. Sizing of fragments was done using the MegaBACE Fragment Profiler 1.3.
The laying A . $m$. capensis mother workers and the sampled brood per colony were analysed according to their relatedness and ploidy level. Arrhenotokously produced individuals show a single allele at all loci. Individuals showing heterozygosity at any of the tested loci are diploid and were thus produced via thelytoky. The genotype of the mother queen and the siring fathers of the laying workers were derived by Mendelian inference from the laying worker genotypes (Estoup et al. 1995).

\subsection{Statistical analyses}

Statistical analyses were done using Statistica 7.0 (StatSoft, Tulsa, OK, USA) and G*Power 3.1.9.2 (Faul et al. 2007). To estimate how accurately the sampling reflects the total number of patrilines, the non-sampling and non-detection errors were calculated following Boomsma and Ratnieks (1996). Chisquared tests were used to test for deviations of the frequency of arrhenotokous and thelytokous workers from a Mendelian segregation assuming a single recessive locus control of thelytoky. Since the within-patriline sample sizes might be small, Fisher's exact tests were used to test for deviations from such a segregation within patrilines and to analyse the association between the mode of parthenogenesis and the occurrence of microsatellite marker haplotypes within the region of the th locus (Lattorff et al. 2007). A power analysis using a generic binomial test was performed to assess whether the experimental sample size was sufficient to gain a power of $\geq 80 \%$. The calculation of the frequency of the thelytoky allele and the exact confidence interval was done based on a binomial distribution (Clopper and Pearson 1934).

\subsection{Re-analysis of Chapman et al. (2015) data}

We re-evaluated the genotype tables provided by Chapman et al. (2015) retaining the original notation of all experimental colonies and all individuals. Individuals with genotypes lacking a maternal and/or a paternal allele at a locus where recombination seemed unlikely (double crossover events over a physical distance of ca. $7 \mathrm{~kb}$ within the th-locus) were classified as not belonging to the pedigree (i.e. an invaded individual). 
After removing these individuals, the raw data were re-analysed to infer the minimum number of laying workers within the sample set using Mendelian inference. It is crucial to use the number of arrhenotokous and thelytokous laying workers rather than the actual number of offspring produced to assess the mode of inheritance of the mode of worker parthenogenesis. Since there were multiple laying workers in all colonies, using the overall number of female and male offspring in the colony is inappropriate for determining the mode of inheritance of worker parthenogenesis, unless all workers lay exactly the same number of offspring.

\section{RESULTS}

\subsection{Mode of parthenogenesis}

The controlled introduction of $A . m$. capensis workers from a single wild colony into the $A . m$. scutellata host colonies resulted in 74 workers for which the mode of parthenogenesis was determined. Thirty-three individuals showed thelytokous and 41 arrhenotokous parthenogenesis (genotypes in Online Resource 1, Tab. S1-S3). This phenotypic distribution did not significantly deviate from a 1:1 ratio (Chi-squared test, $p=0.51$ ). A power analysis revealed that the analysed sample size was sufficient to gain a power of $\geq 80 \%$ (generic binomial test, power $=86 \%$ ). No amphitokous workers showing both modes of parthenogenesis were found.

\subsection{Patrilines and queen alleles}

The 74 thelytokous or arrhenotokous workers could be assigned to 25 patrilines (Fig. 1; genotypes in Online Resource 1, Tab. S4). The low nondetection error $\left(3.3 \times 10^{-5}\right)$ suggests that the number of markers used for genotyping and their polymorphism allows for an unambiguous separation of different individuals. The estimated non-sampling error was 1.5 indicating that we may have missed only up to two patrilines; hence, the sample represents at least $92 \%$ of all present patrilines. Eleven patrilines showed a single mode of parthenogenesis. These patrilines were all represented by a small sample size, mostly with a single tested worker only. Fourteen patrilines comprised both thelytokous and arrhenotokous workers (patrilines 3-16) with a median of 3.5 sampled workers per patriline.

Under the assumption of a single recessive locus control of thelytoky, the father drones either carried the thelytoky or the arrhenotoky allele. Depending on the genotype of the mother queen, this results in different modes of parthenogenesis of the offspring workers, which is shown in detail in Table I. Because the thelytoky allele is recessive (Ruttner 1988, Lattorff et al. 2005), under a single locus model, the occurrence of both types of parthenogenesis within one patriline can only be due to a heterozygous queen (Ar/th) with males carrying the thelytoky allele. Under this assumption, a 1:1 segregation of the two modes of parthenogenesis would be expected per patriline as well as over all patrilines if most workers have a father drone that carried the thelytoky allele. Testing this expected 1:1 segregation within

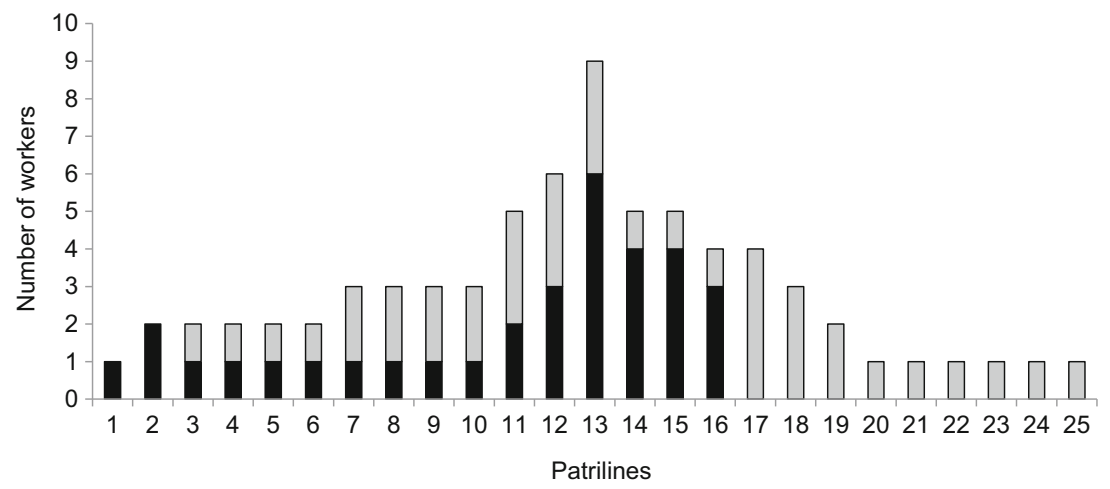

Figure 1. The detected patrilines of the A. m. capensis colony (numbered from 1 to 25 ) and the number of thelytokous (black) and arrhenotokous (grey) workers per patriline $\left(\mathrm{NDE}=3.3 \times 10^{-5}\right)$. 
Table I. The expected genotypes and modes of parthenogenesis of the offspring of drones that either carry the thelytoky $(t h)$ or the arrhenotoky allele $(A r)$ and queens of all possible genotypes $(t h / t h, A r / A r, A r, t h)$ under a single recessive locus control of thelytoky.

\begin{tabular}{|c|c|c|c|}
\hline & Queen $t h / t h$ & Queen $A r / A r$ & Queen $A r / t h$ \\
\hline Drone $t h$ & $\begin{array}{l}100 \% \text { thelytokous } \\
\text { workers }(t h / t h)\end{array}$ & $100 \%$ arrhenotokous workers $(\mathrm{Ar} / \mathrm{th})$ & $\begin{array}{l}50 \% \text { thelytokous workers }(t h / t h)+ \\
50 \% \text { arrhenotokous workers }(\mathrm{Ar} / \mathrm{th})\end{array}$ \\
\hline Drone $A r$ & $\begin{array}{l}100 \% \text { arrhenotokous } \\
\text { workers }(\mathrm{Ar} / \mathrm{th})\end{array}$ & $100 \%$ arrhenotokous workers $(A r / A r)$ & $\begin{array}{l}100 \% \text { arrhenotokous workers } \\
(\mathrm{Ar} / \mathrm{Ar} \text { and } \mathrm{Ar} / \mathrm{th})\end{array}$ \\
\hline
\end{tabular}

patrilines using Fisher's Exact tests for each patriline separately $(p \geq 0.21)$ and a subsequent Fisher's combined probability test $(p=0.997)$ over all patrilines resulted in no significant deviation from this expected 1:1 distribution.

Based on the 27 chromosomal sets sampled (2 from the queen, 25 from the fathers), we estimated the frequency of the thelytoky allele in the population as well as the exact confidence interval (CI) based on a binomial distribution (Clopper and Pearson 1934). Under a single locus model the queen carried one thelytoky and one arrhenotoky allele. Sixteen of the siring drones unambiguously carried the thelytoky allele resulting in a minimum frequency of thelytoky of $\mathrm{p}_{\text {th }}=0.63(17 / 27, \mathrm{CI}$ $0.42-0.81)$. The genotypes of the drones siring exclusively arrhenotokous workers were not certain and can either be thelytoky or arrhenotoky. These workers may have inherited their arrhenotoky allele either by the queen or by the male. The small sample size of these patrilines (17-25) precludes a precise assessment. As we cannot exclude all siring fathers to carry the thelytoky allele, the maximum frequency of thelytoky within the population would be $\mathrm{p}_{\mathrm{th}}=0.96$ (26/27, CI: 0.81-1.00).

\subsection{Tae length polymorphism and allele segregation of the markers flanking gemini in arrhenotokous and thelytokous workers}

The markers flanking gemini did not cosegregate with thelytokous parthenogenesis (genotypes in Online Resource 1, Tab. S5) both over the whole sample set (Chi-squared test, $p=0.52$ ) as well as within single patrilines containing both thelytokous and arrhenotokous individuals
(Fisher exact test, $p$ between 0.20 and 0.75 ). The putative functional mutation of $9 \mathrm{bp}$ (tael) adjacent to the alternatively spliced exon 5 of gemini, the expected thelytoky switch, was found in a homozygous state in only $45 \%$ of the thelytokous workers. Equally, 12 workers homozygous for tael were arrhenotokous instead of thelytokous (genotypes in Online Resource 1, Tab. S6).

\subsection{Re-analysis of Chapman et al. 2015 data}

As Chapman et al. (2015) acknowledge their experiment suffered from recurrent invasions of foreign laying workers into the test colonies, whose offspring was removed from the dataset by using the microsatellite data. However, carefully scrutinizing the genotype data provided in their supplementary tables revealed that this process had not always been fully successful and needed some critical adjustments (see Online Resource 2, Tab. S18S22, S25-S28, S33-S35). We re-evaluated the genotype tables provided by Chapman et al. (2015) by exactly retaining the original notation of all experimental colonies and all individuals. Individuals with genotypes lacking essential maternal and/or paternal alleles at a given locus were classified as not belonging to the pedigree (i.e. an invaded individual; details can be found in Online Resource 2 comprising both the original genotypes of Chapman et al. (2015) and our re-analysis). The corrected sample sizes are given in Table II. The revised data were re-analysed to determine the minimum number of laying workers within the sample set using Mendelian inference (Table II). In particular within the backcross colonies, we inferred a 1:1 segregation for arrhenotoky and thelytoky of laying 
Table II. Corrected numbers of thelytokous and arrhenotokous offspring and the number of inferred reproductive workers in each F1 and backcross (BC) colony respectively

\begin{tabular}{lllllllll}
\hline Colony & $\begin{array}{l}\text { Cross } \\
\text { type }\end{array}$ & $\begin{array}{l}\text { Cross } \\
\text { direction } \\
\text { (queen } \times \\
\text { drone) }\end{array}$ & $\begin{array}{l}\text { Thelytoky } \\
\text { expected }\end{array}$ & $\begin{array}{l}\text { Arrhenotoky } \\
\text { expected }\end{array}$ & $\begin{array}{l}\text { Thelytokous } \\
\text { offspring }\end{array}$ & $\begin{array}{l}\text { Arrhenotokous } \\
\text { offspring }\end{array}$ & $\begin{array}{l}\text { Laying } \\
\text { worker } \\
\text { th }\end{array}$ & $\begin{array}{l}\text { Laying } \\
\text { worker } \\
\text { arrh }\end{array}$ \\
\hline 3 & F1 & SxC & No & Yes & 0 & 47 & 0 & 12 \\
4 & F1 & SxC & No & Yes & 0 & 31 & 0 & 8 \\
7 & F1 & CxS & No & Yes & 0 & 20 & 0 & 7 \\
9 & F1 & CxS & No & Yes & 1 & 16 & 1 & 8 \\
11 & F1 & CxS & No & Yes & $0(1)$ & 15 & 0 & 5 \\
14 & F1 & CxS & No & Yes & 0 & 58 & 0 & 7 \\
10 & BC & $($ SxC)xS & No & Yes & 0 & 8 & nd & nd \\
15 & BC & $($ SxC)xC & Yes & Yes & $19(20)$ & 8 & 4 & 4 \\
16 & BC & $($ SxC)xC & Yes & Yes & $1(26)$ & 1 & 1 & 1 \\
21 & BC & $($ SxC)xC & Yes & Yes & $0(2)$ & 0 & 0 & 0 \\
19 & BC & $(\mathrm{CxS}) \times S$ & No & Yes & 0 & $0(6)$ & 0 & 0 \\
20 & BC & $(\mathrm{CxS}) \times S$ & No & Yes & $17(21)$ & 0 & 12 & 0 \\
22 & BC & $(\mathrm{CxS}) \times C$ & Yes & Yes & $22(23)$ & 0 & 15 & 0 \\
26 & BC & $(\mathrm{CxS}) \times C$ & Yes & Yes & $12(14)$ & 21 & 5 & 5 \\
\hline
\end{tabular}

Original data (Chapman et al. 2015) are shown in parentheses

workers in the colonies 15,16 and 26 matching the predicted segregation under a single locus control (Fisher exact test, $p$ between 0.68 and 1). One hybrid colony (colony 9) showed thelytokous offspring where it is not plausible under a single allele inheritance of thelytoky when following the expectations of Chapman et al. (2015). We here inferred nine laying workers. Eight of them contribute to the production of 15 male offspring (arrhenotokous parthenogenesis), and a single individual

Table III. Alleles and their frequencies in the experimental A . m . scutellata and A.m . capensis populations carried by drone 20 used for breeding backcross colony 20 .

\begin{tabular}{|c|c|c|c|c|c|c|c|c|c|c|c|}
\hline & & A107 & A14 & A29 & A79 & B124 & CSD & $\begin{array}{l}\text { Hb- } \\
\text { the2 }\end{array}$ & $\begin{array}{l}\text { Hb- } \\
\text { the3 }\end{array}$ & $\begin{array}{l}\text { Hb- } \\
\text { the4 }\end{array}$ & tae \\
\hline \multirow{3}{*}{$\begin{array}{l}\text { ָ̃ } \\
\stackrel{0}{0} \\
\stackrel{0}{0}\end{array}$} & $\begin{array}{c}\text { Allele } \\
\text { (bp) }\end{array}$ & 175 & 214 & 129 & 87 & 232 & - & 242 & 189 & 235 & 110 \\
\hline & af $S c$. & 0.1 & 0.2 & $\mathbf{0}$ & 0.2 & 0.1 & - & 0.4 & 0.2 & 0.2 & 0.3 \\
\hline & af Cap. & 0.023 & 0.023 & 0.013 & 0 & 0 & - & 0.12 & 0.02 & 0.33 & 0.56 \\
\hline
\end{tabular}

Subspecies-specific alleles in the drone are highlighted in grey

af Sc allele frequency within experimental 'Scutallata' population; af Cap allele frequency within experimental 'Capensis' population 
Table IV. Comparison between the original analysis of Chapman et al. (2015) and the re-analysis of their data set and this study.

Chapman et al. (2015)

This study and re-analysis of Chapman et al. (2015)

\begin{tabular}{|c|c|c|}
\hline $\begin{array}{l}\text { Method to assess mode of } \\
\text { inheritance of worker } \\
\text { parthenogenesis }\end{array}$ & $\begin{array}{l}\text { Counting the number of offspring } \\
\text { produced per colony }\end{array}$ & $\begin{array}{l}\text { Determining the number of laying workers } \\
\text { per colony based on the genotypes of the } \\
\text { offspring produced per colony }\end{array}$ \\
\hline $\begin{array}{l}\text { Rejection of single locus } \\
\text { control of thelytoky }\end{array}$ & Yes & No \\
\hline Rejection of maternal effects & No & Yes \\
\hline Rejection of paternal effects & Yes & Yes \\
\hline $\begin{array}{l}\text { Rejection of epigenetic } \\
\text { mechanisms }\end{array}$ & No & Yes \\
\hline $\begin{array}{l}\text { Rejection of tae/gemini } \\
\text { (Jarosch et al. 2011) }\end{array}$ & Yes & Yes \\
\hline
\end{tabular}

reproduced thelytokously. This worker, which seems to be a native worker, produced just a single female pupa. Within the backcross colonies, the segregation of thelytoky and arrhenotoky was only inconsistent with the single locus model in colony 20. We therefore present the re-analysis of this colony in more detail here. According to the provided backcross scheme ((Capensis $\times$ Scutellata) $\times$ Scutellata) and under single locus control, this colony should not generate the observed 13 reproductive thelytokous individuals. Unfortunately, the phenotype of the F1 hybrid colony (colony 6) used to generate this backcross is unknown as no natal workers started egg-laying here. Additionally, to test if drone 20 used for insemination of the hybrid queen shows indications of uncertain genotypic origin, we compared its genotype with the alleles of the corresponding 'Capensis' and 'Scutellata' populations, including the genotype data on A. $m$. capensis from our study. The majority of the alleles were inconclusive as they were present in both subspecies (see Table III). However, although two alleles (locus A79 (87 bp) and B124 (232 bp)) are exclusively found in the $A . m$. scutellata workers sampled by Chapman et al. (2015), this drone also carries one allele exclusively found in the $A . m$. capensis population (A29; 129 bp), also present in both F0 A.m. capensis queens used by Chapman et al. (2015).

\subsection{Similarities and differences between the original analysis of Chapman et al. (2015) and the re-analysis of their data set}

A comparative overview between the original analysis of Chapman et al. (2015) and the reanalysis of their dataset and this study is shown in Table IV.

\section{DISCUSSION}

Thelytoky is a rare phenomenon resulting in worker-derived female offspring from unfertilized eggs. In the Cape honeybee, A. $\boldsymbol{m}$. capensis, this mode of parthenogenesis is tightly linked to some other reproductive traits like an early onset of egg-laying (Anderson 1963; Ruttner and Hesse 1981; Moritz and Hillesheim 1985; Plettner et al. 1993) and the production of queen-like amounts of the queen mandibular gland pheromones (Hemmling et al. 1979; Crewe and Velthuis 1980; Moritz et al. 2002; Wossler 2002). Thus, under natural conditions with intra-colonial selection, thelytokous individuals producing the strongest queen-like pheromone signal with the highest amounts of 9-ODA will establish themselves as pseudoqueen and suppress the reproduction of other workers (Moritz et al. 1996, 
2000, 2004; Härtel et al. 2011; Okosun et al. 2015). To avoid this intra-colonial arms race in our experiment, every laying $A . m$. capensis worker was tested individually, which is essential to eventually reveal a Mendelian segregation. We here show that workers produced by a multiply mated $A . m$. capensis queen heterozygous at the th locus (arrhenotoky; thelytoky) reproduce either by arrhenotoky or thelytoky. The two modes of parthenogenesis segregate well in a Mendelian 1:1 ratio predicted by a single recessive locus control.

In contrast, Chapman et al. (2015) reported that thelytokous parthenogenesis in A . $m$. capensis is under multi-locus control. However, a careful analysis of their dataset revealed their results largely confirm our findings and thus also the one locus model for worker thelytoky. The contrasting interpretation of the same dataset results from using the number and genotypes of the actual laying workers within a colony instead of the number of the overall offspring produced in the colony to assess the mode of inheritance of worker parthenogenesis. Using the overall number of female and male offspring produced within the whole colony will suffer from the introduction of a strong bias as not every worker lays exactly the same number of offspring in the colony and worker reproduction can be inhibited or suppressed by intra-colonial selection (Moritz et al. 1996, 2000, 2004; Härtel et al. 2011). Furthermore, re-counting the offspring of an individual will inflate the estimate for the allelic version present in the reproductive worker and hence is a pseudo-replication. If the actual number of reproductive individuals is considered, a distinct 1:1 segregation of both modes of parthenogenesis within colonies showing both arrhenotokous and thelytokous parthenogenesis can be observed. Only two experimental colonies (colony. 9 and 20) of Chapman et al. (2015) do not support the single locus model. According to the crossing scheme for colony 9 (Capensis $\times$ Scutellata) and the backcross scheme for colony 20 ((Capensis $\times$ Scutellata) $\times$ Scutellata) and under single locus control, these colonies should not produce any thelytokous offspring. Whereas in colony 9 (F1 generation) just a single individual did not match the single locus mode by reproducing via thelytoky, 13 individuals in colony 20 (F2 generation) produce female offspring when they should not according to the single locus model. Although we cannot exclude this outcome to be due to an incomplete penetrance of the thelytoky trait or due to a multi-locus control, we suspect this outcome to be most likely caused by insufficient control of the breeding individuals. In particular, the genotype of the putative $\boldsymbol{A}$. $\boldsymbol{m}$. scutellata drone 20 seems to be questionable. If this drone had carried the thelytoky allele instead of the arrhenotoky allele, the entire dataset is in agreement with the one locus model. Indeed, there is reason for concern because this drone carries an allele otherwise only found in the $\boldsymbol{A}$. $\boldsymbol{m}$. capensis lineage. Hence, we have to conclude that the choice of individuals, supposed to have a certain genotype at the thlocus, just based on their geographical origin may be insufficient at best. It ignores the possibility that the putative thelytoky allele may have been present in the Douglas (A.m . scutellata) region due to introgression of thelytoky alleles from the parasitic clone present there (Neumann et al. 2011). It is crucial to test the incidence of the thelytoky/arrhenotoky alleles in the mother colony, and it is crucial to confirm that the chosen drone is offspring of the queen heading the colony. Furthermore, the choice of breeding individuals by geography ignores the occurrence of the arrhenotoky allele in the A. $m$. capensis population at the Cape of Good Hope. Although its frequency might be low, two independent studies found a queen that carries the arrhenotoky allele at the th-locus (Beekman et al. 2009; this study). Therefore, it might be possible that the $\boldsymbol{A} . \boldsymbol{m}$. capensis and A.m. scutellata queens and drones used for crossing may have carried either the arrhenotoky or the thelytoky allele respectively.

Taken together, we see little merit in rejecting the single-locus inheritance of thelytoky in $A . m$. capensis. First, because it requires the fewest assumptions it remains the most parsimonious explanation following Occam's razor 'Pluralitas non est ponenda sine neccesitate'. Only if it is falsified by evidence it should be refused. Second, the single locus control is further supported by the lack of amphitoky (intermediate mode of parthenogenesis) of laying workers in both studies discussed here, as well as in Ruttner (1988) and Lattorff et al. 
(2005). Third, the clear-cut 1:1 segregation pattern and the occurrence of both types of parthenogenesis within a single patriline rule out epigenetic mechanisms or paternal factors determining the mode of parthenogenesis in A. m . capensis. Also, maternal effects other than the alleles of the Mendelian locus can safely be excluded, because otherwise there should be no polymorphism at all among the workers tested in our study. Moreover, a single locus control has also been suggested in other thelytokous Hymenoptera. The allelic origin of asexual reproduction in the parasitoid wasp Lysiphlebus fabarum appears to be controlled by a single locus (Sandrock and Vorburger 2011).

However, we also found that the previously claimed genomic region around gemini on chromosome 13 (Lattorff et al. 2005, Jarosch et al. 2011) does not harbour the locus switching between thelytoky and arrhenotoky in the current study. Nevertheless, although gemini is not the genetic switch for thelytoky in this experimental population, both gemini and the 9-bp deletion (tael ) may be involved in controlling the reproductive capacity in female honeybees which is tightly interwoven in the complex phenotype of the 'thelytoky syndrome' (Lattorff and Moritz 2013). The detection of the actual 'thelytoky switch' will require a concise mapping population coupled with a much higher marker coverage than possible with microsatellite techniques, which is now entirely feasible using SNP marker-based methods (e.g. Stolle and Moritz 2013).

\section{ACKNOWLEDGEMENTS}

We thank Petra Leibe for her technical support. Financial support was granted by the Deutsche Forschungsgemeinschaft (RFAM).

Contributions D. Aumer, R. Moritz, A. Jarosch-Perlow and M. Lattorff designed the study, performed the analysis and wrote the manuscript. D. Aumer and M. Allsopp collected the data

La thélytoquie chez les abeilles du Cap (Apis mellifera capensis ) est contrôlée par un seul locus récessif

Thélytoquie / reproduction des ouvrières / dominance reproductive / reproduction asexuelle / gémini
Die Thelytokie bei der Kapbiene (Apis mellifera capensis) wird durch einen einzigen rezessiven Lokus Kontrolliert

Thelytokie / Arbeiterinnenreproduktion / reproduktive Dominanz / asexuelle Reproduktion / gemini

\section{REFERENCES}

Anderson, R. H. (1963) The laying worker in the Cape honeybee, Apis mellifera capensis . J. Apic. Res. 2, 85-92

Arnold, G., Le Conte, Y., Trouiller, J., Hervet, H., Chappe, B., Masson, C. (1994) Inhibition of worker honeybee ovaries development by a mixture of fatty acid esters from larvae. Cr. Acad. Sci. III-Vie 317, 511-515

Baudry, E., Kryger, P., Allsopp, M., Koeniger, N., Vautrin, D., Mougel, F., Cornuet, J. M., Solignac, M. (2004) Whole-Genome scan in thelytokous-laying workers of the Cape honeybee (Apis mellifera capensis): central fusion, reduced recombination rates and centromere mapping using half-tetrad analysis. Genetics 167, 243-252

Beekman, M., Allsopp, M. H., Jordan, L. A., Lim, J., Oldroyd, B. P. (2009) A quantitative study of worker reproduction in queenright colonies of the Cape honey bee, Apis mellifera capensis. Mol. Ecol. 18, 2722-2727

Boomsma, J. J., Ratnieks, F. L. W. (1996) Paternity in eusocial Hymenoptera. Phil. Trans. Roy. Soc. B 351, 947-975

Butler, C. G. (1959) The source of substance produced by a queen honeybee which inhibits development of the ovaries of the workers of her colony. Proc. R. Ent. Soc. A 34, 137-138

Chapman, N. C., Beekman, M., Allsopp, M. H., Rinderer, T. E., Lim, J., Oxley, P. R., Oldroyd, B. P. (2015) Inheritance of thelytoky in the honey bee Apis mellifera capensis. Heredity 114, 584-592

Clopper, C. J., Pearson, E. S. (1934) The use of confidence or fiducial limits illustrated in the case of the binomial. Biometrika 26, 404-413

Crewe, R. M., Velthuis, H. H. W. (1980) False queens: A consequence of mandibular gland signals in worker honeybees. Naturwissenschaften 67, 467-469

Crozier, R. H. (1975) Animal Cytogenetics. Borntraeger, Berlin.

Estoup, A., Scholl, A., Pouvreau, A., Solignac, M. (1995) Monoandry and polyandry in bumble bees (Hymenoptera; Bombinae) as evidenced by highly variable microsatellites. Mol. Ecol. 4, 89-94

Faul, F., Erdfelder, E., Lang, A.-G., Buchner, A. (2007) G*Power 3: A flexible statistical power analysis program for the social, behavioral, and biomedical sciences. Behav. Res. Methods 39, 175-191

Härtel, S., Wossler, T., Moltzer, G.-J., Crewe, R., Moritz, R. F. A., Neumann, P. (2011) Pheromone-mediated reproductive dominance hierarchies among pseudo-clonal 
honeybee workers (Apis mellifera capensis). Apidologie 42, 659-668

Hemmling, C., Koeniger, N., Ruttner, F. (1979) Quantitative Bestimmung der 9-Oxodecensäure im Lebenszyklus der Kapbiene (Apis mellifera capensis Escholtz). Apidologie 10, 227-240

Jarosch, A., Stolle, E., Crewe, R. M., Moritz, R. F. A. (2011) Alternative splicing of a single transcription factor drives selfish reproductive behaviour in honeybee workers (Apis mellifera). Proc. Natl. Acad. Sci. 108, $15282-15287$

Kirby, K. S. (1956) A New Method for the Isolation of Ribonucleic Acids from Mammalian Tissues. Biochem. J. 64, 405-408

Kraus, F. B., Neumann, P., van Praagh, J., Moritz, R. F. A. (2004) Sperm limitation and the evolution of extreme polyandry in honeybees (Apis mellifera L.). Behav. Ecol. Sociobiol. 55, 494-501

Lattorff, H. M. G., Moritz, R. F. A. (2013) Genetic underpinnings of division of labor in the honeybee. Trends Genet. 29, 641-648

Lattorff, H. M. G., Moritz, R. F. A., Fuchs, S. (2005) A single locus determines thelytokous parthenogenesis of laying honeybee workers (Apis mellifera capensis). Heredity 94, 533-537

Lattorff, H. M. G., Moritz, R. F. A., Crewe, R. M., Solignac, M. (2007) Control of reproductive dominance by the thelytoky gene in honeybees. Biol. Lett. 3, 292-295

Moritz, R. F. A., Hillesheim, E. (1985) Inheritance of dominance in honeybees (Apis mellifera capensis). Behav. Ecol. Sociobiol. 17, 87-89

Moritz, R. F. A., Kryger, P., Allsopp, M. H. (1996) Competition for royalty in bees. Nature $\mathbf{3 8 4}, 31$

Moritz, R. F. A., Simon, U. E., Crewe, R. M. (2000) Pheromonal contest between honeybee workers (Apis mellifera capensis ). Naturwissenschaften 87, 395-397

Moritz, R. F. A., Crewe, R. M., Hepburn, H. R. (2002) Queen avoidance and mandibular gland secretion of honeybee workers (Apis mellifera L.). Insectes Soc. 49, 86-91

Moritz, R. F. A., Lattorff, H. M. G., Crewe, R. M. (2004) Honeybee workers (Apis mellifera capensis) compete for producing queen-like pheromone signals. Proc. R. Soc. Lond. B 271, 98-100

Moritz, R. F., Pirk, C. W., Hepburn, H. R., Neumann, P. (2008) Short-sighted evolution of virulence in parasitic honeybee workers (Apis mellifera capensis Esch.). Naturwissenschaften 95, 507-513

Moritz, R. F. A., Lattorff, H. M. G., Crous, K. L., Hepburn, R. H. (2011) Socialparasitism of queens and workers in the Cape honeybee (Apis mellifera capensis). Behav. Ecol. Sociobiol. 65, 735-740

Neumann, P., Hepburn, R. (2002) Behavioural basis for social parasitism of Cape honeybees (Apis mellifera capensis ). Apidologie 33, 165-192

Neumann, P., Härtel, S., Kryger, P., Crewe, R. M., Moritz, R. F. A. (2011) Reproductive division of labour and thelytoky result in sympatric barriers to gene flow in honeybees (Apis mellifera L.). J. Evol. Biol. 24, 286-294

Okosun, O. O., Yusuf, A. A., Crewe, R. M., Pirk, C. W. (2015) Effects of age and Reproductive Status on Tergal Gland Secretions in Queenless Honey bee Workers Apis mellifera scutellata and A.m. capensis . J. Chem. Ecol. 41, 896-903

Onions, G. W. (1912) South african "fertile-worker bees". S. Afr. Agric. J. 1, 720-728

Page, R. E., Erickson, E. H. (1988) Reproduction by worker honey bees (Apis mellifera L.). Behav. Ecol. Sociobiol. 23, 117-126

Plettner, E., Slessor, K., Winston, M., Robinson, G., Page, R. (1993) Mandibular gland components and ovarian development as measures of caste differentiation in the honey bee (Apis mellifera L.). J. Insect. Physiol. 39, $235-240$

Ruttner, F. (1988) Taxonomy and Biogeography of Honeybees. Springer, Berlin.

Ruttner, F., Hesse, B. (1981) Rassenspezifische Unterschiede in Ovarentwicklung und Eiablage von weisellosen Arbeiterinnen der Honigbiene Apis mellifera L. Apidologie 12, 159-183

Sandrock, C., Vorburger, C. (2011) Single-locus recessive inheritance of asexual reproduction in a parasitoid wasp. Curr. Biol. 21, 433-437

Shaibi, T., Lattorff, H. M. G., Moritz, R. F. A. (2008) A microsatellite DNA toolkit for studying population structure in Apis mellifera. Mol. Ecol. Res. 8, 1034-1036

Slessor, K. N., Kaminski, L.-A., King, G. G. S., Borden, J. H., Winston, M. L. (1988) Semiochemical basis of the retinue response to queen honey bees. Nature 332, 354-356

Solignac, M., Vautrin, D., Loiseau, A., Mougel, F., Baudry, E., Estoup, A., Garnery, L., Haberl, M., Cornuet, J.-M. (2003) Five hundred and fifty microsatellite markers for the study of the honeybee (Apis mellifera L.) genome. Mol. Ecol. Notes 3, 307-311

Stolle, E., Moritz, R. F. A. (2013) RESTseq - Efficient Benchtop Population Genomics with RESTriction Fragment SEQuencing. PlosOne 8, e63960

Verma, S., Ruttner, F. (1983) Cytological analysis of the thelytokous parthenogenesis in the Cape honeybee (Apis mellifera capensis Escholtz). Apidologie 14, 41-57

Visscher, P. K. (1989) A quantitative study of worker reproduction in honey bee colonies. Behav. Ecol. Sociobiol. 25, 247-254

Winston, M. L. (1987) The Biology of the Honey Bee. Harvard University Press, London.

Winston, M. L., Slessor, K. N. (1998) Honey bee primer pheromones and colony organization: gaps in our knowledge. Apidologie 29, 81-95

Wossler, T. C. (2002) Pheromone mimicry by Apis mellifera capensis social parasites leads to reproductive anarchy in host Apis mellifera scutellata colonies. Apidologie 33, 139-163 